\title{
The effect of diet on the development of the adipose organ
}

By Douglas Gairdner, Addenbrooke's Hospital, Cambridge and Joy Dauncey, University of Cambridge and Medical Research Council, Dunn Nutritional Laboratory, Cambridge

The possibility that an infant's diet may influence the later development of obesity or of atheroma gives this subject its interest and importance.

The concept of the body's depot fat as constituting an 'organ' is probably a useful one, but only so long as it does not lead to unwarranted simplification. For instance, samples of depot fat taken from the adipose tissue of a baby's buttock tend to have larger fat cells than those from the abdominal wall, so that we must be cautious before assuming that single fat samples are representative of all depot fat.

Chemical composition. The lipid laid down in the depot fat of a mammal generally reflects the chemical constitution of the fats fed to it, and this applies equally in the human species. Fig. I illustrates how the fatty acid composition of the triglyceride of the baby's adipose tissue is determined by the type of fat in the milk it receives.

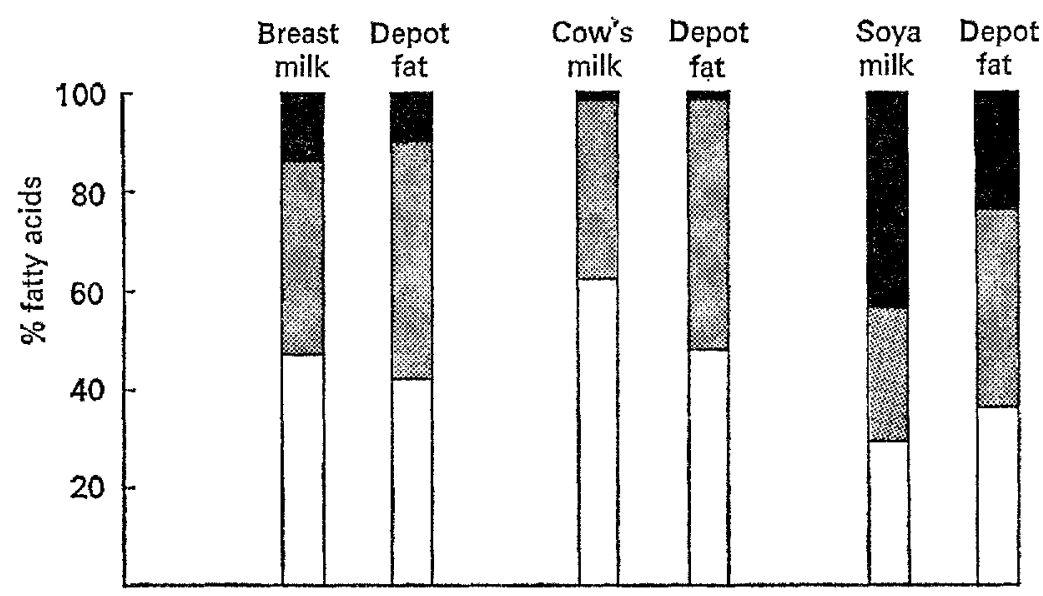

Fig. I. Fatty acid composition of triglycerides of depot fat of infants aged 6 weeks compared with that of their milk feed. Polyunsaturated fatty acid, $\quad$; monounsaturated, 7 ; saturated, $\square$. Results from Sweeney; Etteldorf, Throop, Timma \& Wrenn (I963) and Ballabriga, Martinez \& Gallart-Catala (1972).

If a baby is artificially fed, therefore, we inevitably impose upon its depot fat a predictable chemical pattern. A serious responsibility must consequently rest on those who determine the type of milk formula to be used in a maternity hospital, or who advise mothers how to feed their babies, or who influence the types of milk preparations put on the market by commercial firms.

Fig. 2 shows the great diversity of the fat component of some of the milks commonly used to feed babies. Not shown here is the fat composition of Almiron B, 
a preparation used extensively in Holland, and notable for the very high content of linoleic acid: $58 \%$ of the fatty acids. It is worth noting that the depot fat normally laid down by the foetus contains very little ( $1 \%$ or less) linoleic acid, raising the question of whether it is advisable to feed a pre-term baby with a milk rich in linoleic acid. If this is done, as is common practice in some units, the baby's fat rapidly acquires a high linoleic acid content, which (it might be argued) is unphysiological at this stage.

Depot fat

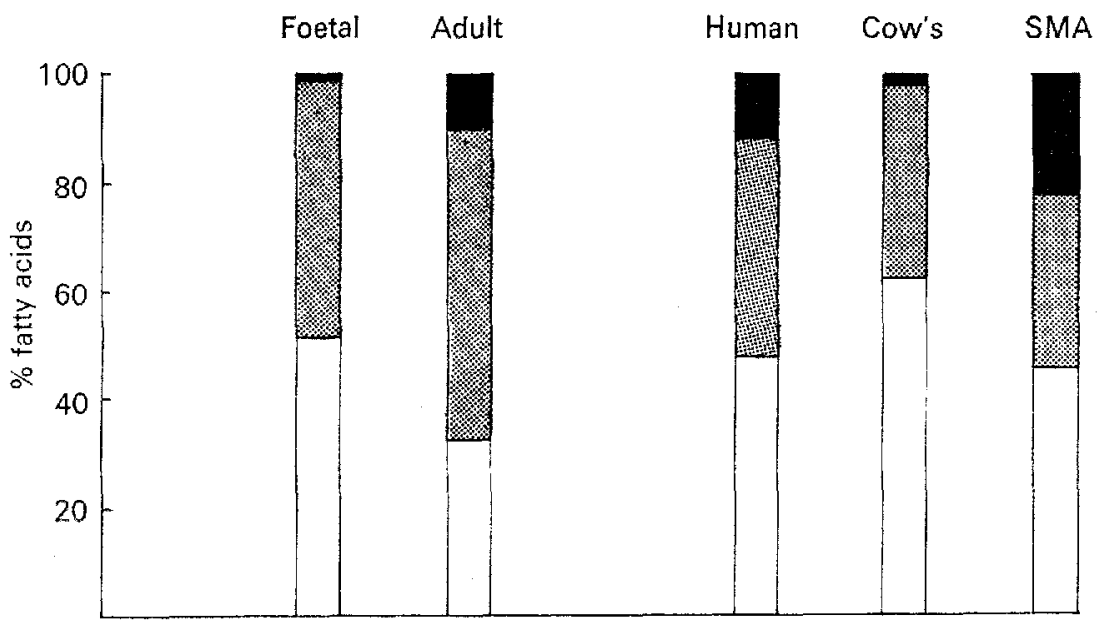

Fig. 2. Fatty acid composition of triglycerides of human, cow's and SMA (artificial) milk, and of foetal and adult depot fat. Note the low proportion of unsaturated fatty acid, particularly linoleic, in the infant before birth compared with later. Linoleic acid, D; unsaturated fatty acids, [0; saturated fatty acids, $\square$.

However, as regards the consequences, short- or long-term, of the type of lipid laid down by the baby in the first months of life, nothing certain is known, although it seems unlikely that no consequences exist.

Fat cell size and multiplication. The diameter of fat cells in adipose tissue can be measured by viewing, by direct microscopy, a $200 \mu \mathrm{m}$ section of a fragment of tissue, sectioned after freezing. Samples of adipose tissue have been obtained at surgical operation, post mortem, or by needle biopsy. Fig. 3 shows the res alts for a series of babies from 24 weeks gestation to about I year of age. At 28 wecks gestation, the mean diameter of fat cells is about $40 \mu \mathrm{m}$, at term about $65 \mu \mathrm{m}$, and at 6 months about I IO $\mu \mathrm{m}$. The ratios of the mean volumes $\left(\right.$ diameter $\left.^{3}\right)$ of the fat cells at these three ages can then be estimated to be about $1: 4: 20$. Between 28 and 40 weeks the foetus increases its total body fat from about $40 \mathrm{~g}$ to $420 \mathrm{~g}$, i.e. about Io-fold. Since the volume of the fat cell in the same period increases only 4 -fold, appreciable fat cell multiplication must take place during the last trimester of foetal life. (Total body fat has been estimated in infants by a method (unpublished) involving skinfold measurements.) 


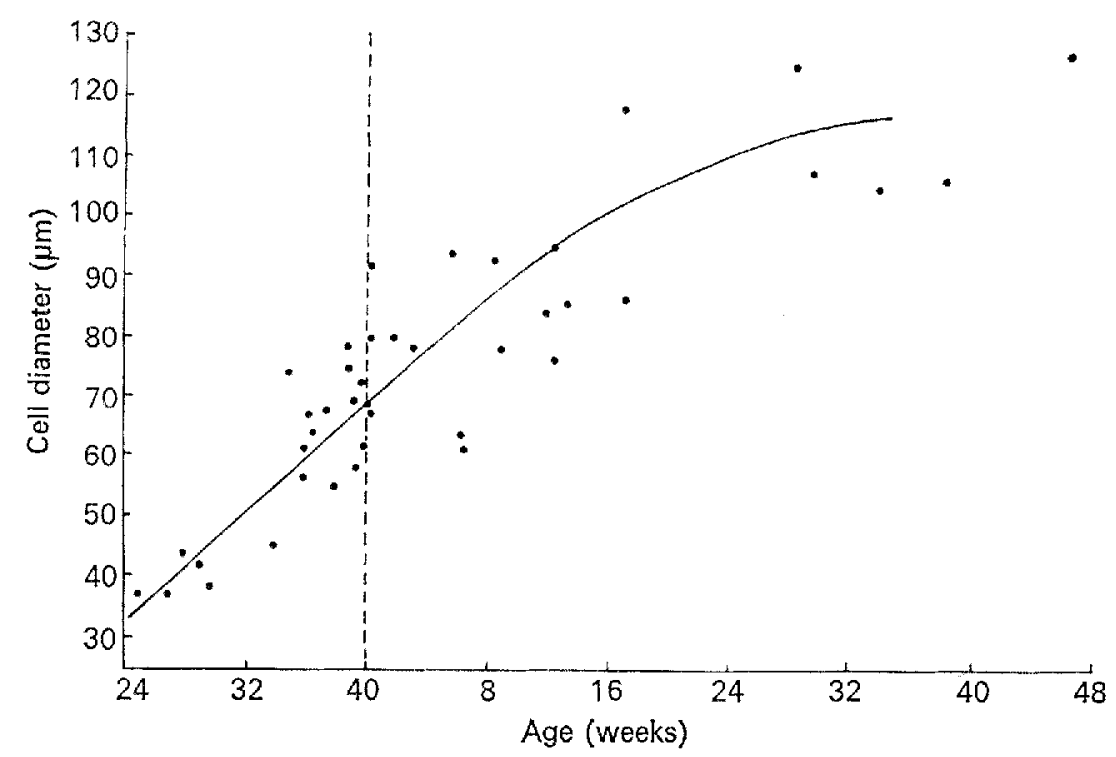

Fig. 3. Mean diameter of fat cells of human adipose tissue from 24 weeks foetal life, to age $4^{8}$ weeks.

If we apply the same rough quantitative approach to the next phase of growth, from birth to 6 months the total body fat increases from about $420 \mathrm{~g}$ to $1500 \mathrm{~g}$, or less than 4 -fold. This compares with the approximately 5 -fold increase in fat-cell volume in the same period. These data therefore lead to the conclusion that during the first 6 months of life, cell multiplication cannot be great, since the increase in the body's fat seems to be largely accounted for by the conspicuous increase in cell size. This conclusion must however be strictly tentative, since it is derived from cross-sectional data, and not from sequential observations made on individual subjects, with fat samples all taken from the same anatomical site.

While overfeeding a baby certainly leads to an abnormally large gain in his total body fat, we are not yet in a position to say whether his total complement of fat cells is unduly multiplied, or merely that his existing fat cells grow unduly large.

\section{REFERENCES}

Ballabriga, A., Martinez, A. \& Gallart-Catala, A. (1972). Helv. paediat. Acta 27, 91.

Sweeney, M. J., Etteldorf, J. N., Throop, L. J., Timma, D. L. \& Wrenn, E. L. (1963). F. clin. Invest. 42,1 . 